\title{
Creating an Academic Community of Inquiry: Educating Architects to Embrace a People-Centered View
}

\author{
LAUREN MATCHISON \\ University of Southern California
}

It can be argued that pedagogy which privileges technology now dominates university-level architecture curriculum and culture. The result of this latest phase of determinism accelerates the distancing of the design process from both the people it is intended to serve and the natural and built environment that architecture should relate to, as it has in the increasingly distant past. However, not all practitioners or educators support this trend. A contrarian view has recently gained momentum, and this paper addresses the re-emergence of a people-centered agenda in the form of public interest architecture. Ideas explored here pay special attention to developing a culture of 'community of inquiry' within architectural pedagogy, one that thoroughly incorporates social issues and more accurately reflects the collaborative nature of contemporary architectural practice. First, the paper establishes an understanding of the concept of a community of inquiry, and its relationship to architectural pedagogy. It then illustrates that an academic community of inquiry naturally fosters multidimensional thinking and supports the development of empathy and high 'other-focus,' which is the ability to concentrate on the interest and well-being of others. Finally, it considers two effective professional models of communities of inquiry in public interest architecture: MASS Design Group and Kéré Architecture. The paper ultimately argues that a new educational model is needed which mediates Positivism and embraces people, advancing sensitive design solutions which deeply engage local social, economic and ecological issues.

\section{INTRODUCTION}

Since it became attached to the relentless commodification cycle of capitalism at the beginning of the Machine Age, the profession of architecture has experienced a rapidly revolving door of stylistic shifts, from Modernism to its post-industrial antithesis, followed by Deconstructivism and Sustainability. Each expired with an increasingly rapid half-life until we are left with Parametricism today, as the latest amplified phase of technological determinism, driven by a pervasive global economic imperative. This latest phase has further accelerated the distancing of the design process from both the people it is intended to serve and the natural and built environment that architecture should relate to, as it has in the increasingly distant past.

This position of technological dominance, that Alberto Perez-Gomez has clearly enunciated as a crisis, remains unchallenged in pedagogy today, as demonstrated by the continual conversion of questions concerning value and meaning into parameters that functionally define form. ${ }^{1}$ Current pedagogy dangerously abstracts context, de-emphasizes collaboration, and subdues social dialogue. This attitude often manifests in studio projects unanchored in place and time. Project briefs fail to acknowledge specific and subjective human conditions, encouraging students to rely on personal assumptions and biases, which leaves them unable to explore in a sensitive way beyond their own culture. The fear, then, is that students educated in such a way will be limited to designing spaces that are homogenous and disconnected from human values and meaning, as well as the increasingly imperiled natural world.

\section{AN ALTERNATIVE VIEW}

However, a contrarian view, that the built environment must reflect human consciousness, and should accommodate social, cultural, political, religious, historical and environmental factors is slowly gaining momentum. This alternative, people-focused view is certainly not new, it is reflected in the public interest design movement taking shape across America and in other countries to fulfill these unmet public needs, which asserts that the field of architecture will improve the built environment's social, economic, and environmental conditions more effectively if a significant segment of practice is directly engaged in such work. ${ }^{2}$

The goal of this paper is to imagine an educational model which embraces such a view, one based on the concept of a community of inquiry adapted for architecture pedagogy in studio and non-studio environments, one that mediates Positivism and reinserts human interest into the design process, and ultimately prepares students to join the burgeoning public interest architecture movement.

The first step, then, is to establish an understanding of the concept of a community of inquiry, and how it might relate to architecture pedagogy. The next step is to illustrate that a community of inquiry fosters multidimensional thinking and supports the development of empathy and of what has been called high 'other-focus,' which is the ability to concentrate on the interest and well-being of others. The final step, is to consider effective models of communities of inquiry in contemporary practice. 


\section{COMMUNITY OF INQUIRY AND ITS RELEVANCE IN ARCHITECTURE EDUCATION}

The concept of a community of inquiry is well-known to educators familiar with the Pragmatist philosophy of Charles Sanders Peirce and John Dewey. Dewey, a student of Peirce's, staunchly believed that students should investigate problems and engage in inquiry for themselves, rather than to blindly receive information from a teacher. The classroom, Dewey advocated, is a place for imaginative, independent, and most importantly, reflective thinking. Principally, he recognized that all education is essentially inquiry.

Dewey's mentor, Peirce, authored the phrase 'community of inquiry' and originally applied to it scientific inquiry alone. Dewey embraced and expanded the term to apply to the arts, to education, and to many other areas of learning. Regardless of scientific or non-scientific boundaries, Peirce's term refers to what he described as: "a community similarly dedicated to the use of like procedures in pursuit of identical goals." ${ }^{3}$ According to leading education theorist Matthew Lipman, a community of inquiry is generally one "in which students listen to one another with respect, build on one another's ideas, challenge one another to supply reasons for otherwise unsupported ideas, assist each other in drawing inferences from what has been said, and seek to identify one another's assumptions." ${ }^{4}$ In synthesizing the ideas, a picture begins to emerge of a democratic and peer-mediated learning environment which values curiosity, exploration, and self-criticism, and holds dialogue and collaboration as fundamental premises. Given its origins in Pragmatist philosophy, literature on the subject of community of inquiry predictably focuses on pedagogical application in philosophical and moral education. However, the transmission to architectural pedagogy is not unreasonable, as the typical learning environment in studios and non-studio seminars is inherently similar to those found within a community of inquiry.

Some architecture faculty may pause here, and declare that the democratic nature of a community of inquiry is seemingly at odds with traditional hierarchical academic design studio methodology which still flourishes in many schools. Yet one can imagine a paradigm emerging in which the instructor is the facilitator rather than the master, one who embraces and values collaboration and peer-mediated dialogue above individual pursuit. Such a model would avoid reinforcing the view of architecture as a result of individualistic work. ${ }^{5}$ This desirable realignment of values may more accurately reflect the collaborative nature of contemporary architectural practice.

\section{THREE WAYS OF THINKING: CRITICAL, CREATIVE, AND CARING}

Once one invests in the idea of a democratic, faculty-facilitated studio and seminar model rooted in collaboration, dialogue, and inquiry, one can envision each as a vehicle for multidimensional thinking. This type of thinking naturally occurs in a community of inquiry because of its ability to engage the dimensions of criticality, creativity, and caring.

\section{CRITICAL THINKING}

Dewey and his emphasis on reflective thinking a century ago served as the precursor to the critical thinking movement. The following definition by educational psychologist and authority on critical thinking, Linda Elder, is especially relevant to nurturing criticality within architecture students: "People who think critically consistently attempt to live rationally, reasonably, empathically...They work diligently to develop the virtues of intellectual integrity, intellectual humility, intellectual civility, intellectual empathy, intellectual sense of justice and confidence in reason." ${ }^{1 t}$ It follows that these intellectual virtues should be habitual for people who design spaces for others.

Philosophically speaking, critical thinking facilitates judgment because it relies on criteria, is self-correcting, and is sensitive to context. ${ }^{7}$ Within this framework, an architectural 'judgment' is a concrete one: a designed and built space. Architecture resulting from uncritical thinking and unreflective action is imprecise and arbitrary. The risk is that divorcing contextual specificity from pedagogy will produce an ill-defined result, which cannot be judged by any standards of appropriateness, one that is in danger of becoming nothing more than a meaningless abstraction.

In fact, Lipman warns that "critical thinking in this sense is a descendent of Aristotle's awareness that individual situations need to be examined on their own terms and not forced into some Procrustean bed of general rules and regulations." 8 In this light, the abstraction of values and meaning in design projects voids sensitivity to context and therefore renders critical thinking unlikely, if not impossible. This serves as a poignant reminder that while it is generally accepted that current architectural design pedagogy does in fact endorse critical thinking, it must do so in totality, rather than selectively.

\section{CREATIVE THINKING}

Architecture is generally accepted to be a creative undertaking, so the second category of creative thinking should be readily incorporated since it involves cognitive processes including perception, imaging, analyzing and synthesizing. ${ }^{9}$ Architecture students experience creativity in the form of inspiration resulting from critical thinking combined with skills and ability, applied to design problems. Historically, creativity has been understood as intrinsic and self-actualized. Mainly as inspired thinking primarily emanating from within the creative person. In his recent book on design education, Ashraf Salama discusses the radical rethinking of the understanding of creativity to include extrinsic influences of the social, environmental, and cultural aspects. He contends that "creativity thus becomes a dialogue between the materials of the situation, an integration of both intrinsic and extrinsic influences." ${ }^{10}$ 
Criticality and creativity are clearly interdependent. The merely critical thinker is conservative, searching for an appropriate judgment that will cement a solution. On the other hand, creative thinkers are skeptical, they amalgamate disparate influences and imagine new solutions. ${ }^{11}$ Creative thinking thus provokes and produces both appreciation and criticism, a feedback loop which invites reflective thinking.

\section{CARING THINKING AND THE ENCOURAGEMENT OF EMPATHETIC THINKING AND HIGH OTHER-FOCUS}

Often, the aspect of caring thinking, which is the third category described here, is completely absent in architecture pedagogy. Some in academia may struggle to give equal weight to caring thinking, as it is often perceived as less rigorous or related only to emotional reactions. Yet emotion related to caring provides our thoughts with framework and perspective. To care means to value something, to carefully consider something, to respect and appreciate its worth. Undoubtedly architecture students exhibit care. They care deeply about the time and energy they invest in a project, the reception a completed project receives, and the impression it makes on faculty and peers. People care about things that matter. Yet caring means thinking beyond one's self. Caring implies the ability to think and react empathetically toward others.

Regrettably, the currently entrenched nature of Positivism leaves little room for emotion. However, communities of inquiry naturally support the development of care and empathy, as they are coherent environments for thinking of others to flourish. When it comes to intellectual empathy, the critical and caring dimensions are deeply intertwined.

Simply put, empathy is the ability to understand and share the feelings of another. This type of caring involves imagining the perspectives of others beside ourselves. Empathetic thinking is only possible when we have people to imagine, and as such it is ethical. Pedagogy that abstracts or entirely removes the client, the person, or the people that the building intends to serve cannot possibly educate students for the world in which they will practice. Recall Elder's emphasis on the virtues of intellectual humility and intellectual empathy inherent in critical thinking. This is refined in her assertion that improved thinkers encompass:

...the intellectual empathy necessary to put oneself in the place of others in order to genuinely understand them, the intellectual courage to face and fairly address ideas, beliefs, or viewpoints toward which one has strong negative emotions, the fair-mindedness necessary to approach all viewpoints without prejudice, without reference to one's own feelings or vested interests. ${ }^{12}$

While Elder is clearly describing the merits of improved thinkers, such characteristics naturally bring to mind people who exhibit high 'other-focus.'
Other-focus is one's responsiveness to the interest and well-being of others. High other-focus is a characteristic of humility. Professor Thomas Nadelhoffer and his colleagues in philosophy and psychology recently wrote about this desirable aspect of humility in the Journal of Moral Philosophy and described it as such:

Because humility facilitates a realistic appraisal of ourselves, it removes (or reduces) the need to inflate or deflate our own value or significance... and it is this 'unencumbered' encountering of others as individuals in their own right that (a) facilitates an appreciation of and compassion for their welfare, and (b) increases our attention on (and interest in) its protection and promotion. ${ }^{13}$

Protecting the health, safety, and welfare of all people is a fundamental tenet of the architecture profession. One can imagine that a community of inquiry existing within architecture pedagogy would naturally encourage, cultivate, and value the views of others, expanding the perspectives of students in the process. Perhaps high other-focus is a natural consequence of such a community, one committed to creating architecture that puts people first.

\section{IMPROVED THINKING IS MULTIDIMENSIONAL}

A community of inquiry is a deliberative society engaged in multidimensional thinking whose aim should be improved thinking; thinking that unites criticality, in its entirety, with creativity and caring. Importantly, these three dimensions are transactional, rather than independent, and improved thinking results when they are in equilibrium. ${ }^{14}$ These three interdependent dimensions are at work simultaneously in the mind of an architecture student. When confronting a design problem, the critical aspect is looking for any solution which soundly fulfills the criteria. The creative aspect searches for an imaginative solution; and the caring aspect seeks a solution because he or she cares about the people affected by the situation. A people-centered pedagogy readily embraces the equity inherent within multidimensional thinking due to its desire to accommodate human consciousness in all aspects. The reality of a pedagogical framework which supports critical and creative thinking, yet dismisses the equivalent dimension of caring thinking is bleak, for when caring is absent, indifference and apathy are imminent.

If one imagines the education of an architect as embracing these three aspects of thinking equally, it could end the perceived stalemate between Parametricism and a peoplecentered view. The three-legged stool of multidimensional thinking aims at a balance between the cognitive and the affective, between the perceptual and the conceptual. This is the balance that current pedagogy lacks. 


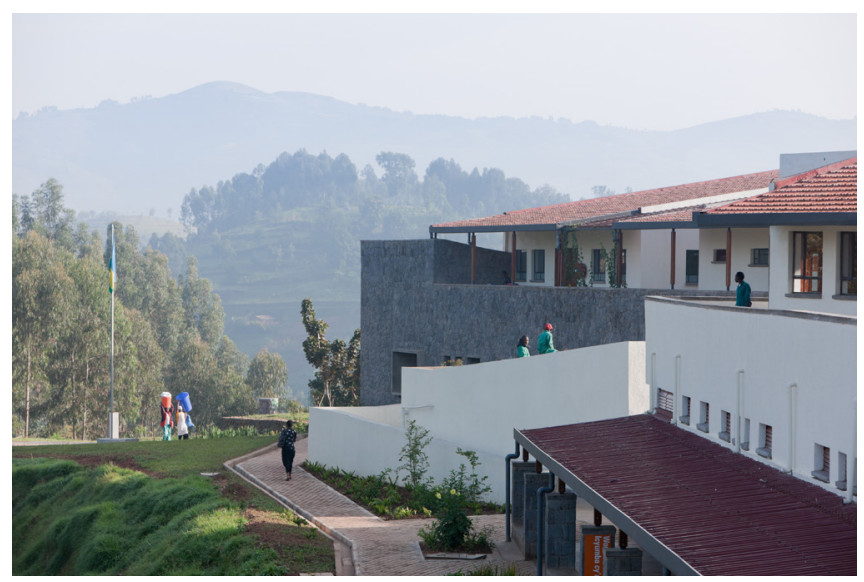

Figure 1: Butaro District Hospital, Northern Province, Rwanda, MASS Design Group. CI wan Baan

\section{EFFECTIVE MODELS OF COMMUNITY OF INQUIRY IN CONTEMPORARY ARCHITECTURAL PRACTICE}

A people-centered ethos is arguably emerging most visibly in the areas of health and education, perhaps because these are the arenas in which empathy is most important. This developing movement, referred to as public interest architecture, engages projects that address long-term societal problems and have broad public benefit. Such projects embed local social, economic, and ecological issues into sensitive design interventions meant to positively impact local people and communities. ${ }^{15}$

The remaining sections of this paper examine two design firms currently engaged in public interest architecture, whose built projects are clear examples of value-laden work. Although each of these firms have produced various types of buildings and practice in completely different parts of the world, their design processes and methods are analogous. John Dewey and his Pragmatist colleagues would likely agree that each of these firms serve as an effective model of a community of inquiry in their respective practices.

In the realm of health, MASS Design Group's methodology and buildings clearly demonstrate a positive impact on local communities in Rwanda. In the area of education, Kéré Architecture readily embraces a robust people-centered agenda in Burkina Faso.

Each firm expands the community of inquiry beyond the design team itself, to include the users, client, and local agencies as contributing members. Collaboration, dialogue, empathy, and inquiry are the bedrock on which these firms are anchored.

\section{HEALTH: MASS DESIGN GROUP + PARTNERS IN HEALTH + RWANDAN MINISTRY OF HEALTH}

Michael Murphy and Alan Ricks founded MASS in 2008 as a 501(c)(3) non-profit organization, so that they could, in their words: "...create a model of practice optimized to deliver

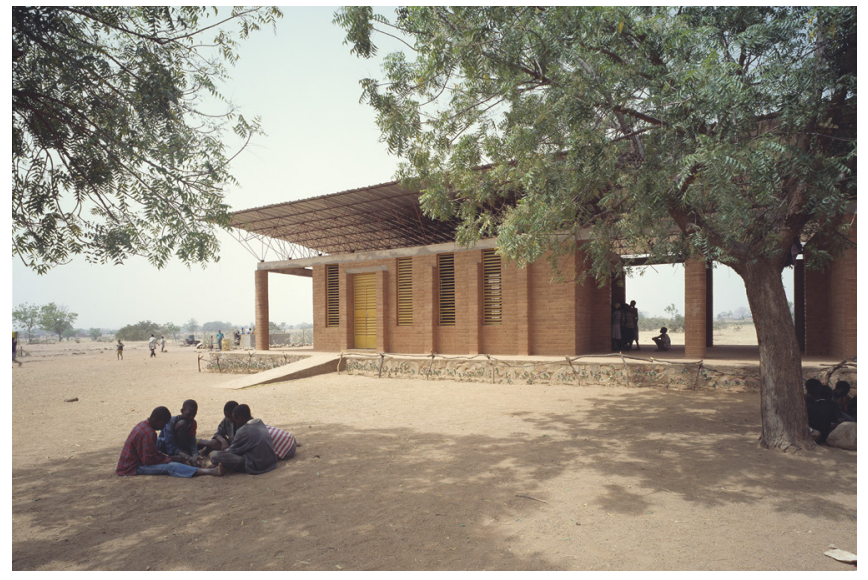

Figure 2: Gando Primary School, Gando, Burkina Faso, Kéré Architecture. IAA0173 CAga Khan Trust for Culture / Siméon Duchoud (photographer)

maximum impact to our partners and the communities they serve." ${ }^{16}$ The first project they designed was the Butaro District Hospital in the Northern Province of Rwanda (figure 1), completed in 2011, in collaboration with the Rwandan Ministry of Health, and Dr. Paul Farmer, the co-founder of Partners in Health (PIH). MASS Design Group and PIH's partnership created a holistic model of architecture that choreographed the process of construction to employ, educate, and empower the local community. The hospital design is site specific and mitigates the transmission of airborne disease using passive ventilation techniques and optimal orientation strategies. Local volcanic rock from the Virunga mountain chain and local labor delivered site-appropriate, sustainable design, and stimulated the local economy. ${ }^{17}$ The collaboration also produced Butaro Doctor's Housing in 2012 and Butaro Ambulatory Cancer Center in 2013.

MASS is an acronym for Model of Architecture Serving Society. A cursory overview of their more than 40 completed projects involving health care, environmental equity and education, in which the client is always a design partner, validates their name. The firm foregrounds collaboration, an approach evident in the way they seek new work. MASS does not often submit RFPs or enter competitions, instead, Director of Design David Saladik notes that projects often materialize "...through a desire to support great partners or to work with specific individuals. We reach out and say, 'How can we support you?"'18 Engaging in dialogue from the outset is deeply embedded in MASS's process and clearly aligns with the principles of a community of inquiry.

MASS has already begun to translate their model of practice into an educational one, in that they actively seek to educate, train, and empower socially-minded architects. The firm created the African Design Centre (ADC), in Kigali, Rwanda, to fulfill this mission. MASS designed the twenty-month fellowship to complement traditional architecture education. The curriculum combines typical technical skills with "... humanities workshops focused on storytelling, history, social 
justice, international development, and leadership.."19 The inclusion of storytelling in the curriculum is noteworthy; it acts as a pedagogical tool for triggering a person's empathetic response. Humans are imaginative creatures; our empathy is easily aroused when one person takes the role or situational perspective of another person. ${ }^{20}$ Matthew Schertz, an expert on teaching and learning, writes that empathetic imagination can be stirred by the telling of an emotionally rich experience. ${ }^{21}$ Empathetic imagination demonstrates the ability of a person to understand the perspective of another. This perspective-taking is other-focused, in that one can imagine how the other person feels or how most people would feel in that situation. By prioritizing stories, empathy is embedded within the curriculum and the community.

MASS Design Group's pedagogic and design strategies reveal a commitment to the values of humility, care, and high otherfocus, which, in the case of the Butaro District Hospital, translate to measurable improvements in the health of local people.

\section{EDUCATION: KÉRÉ ARCHITECTURE + KÉRÉ FOUNDATION}

Diébédo Francis Kéré is the principal and founder of Kéré Architecture, based in Berlin. Kéré grew up in Gando, Burkina Faso; a small village which lacked electricity, running water, and schools. His father, who was the head of the village, allowed Kéré to move to Germany to study when he was seven years old. Kéré stayed in Germany and eventually earned a university degree in architecture and engineering. As the first person from his village to have access to higher education abroad, Kéré became convinced that education was the cornerstone of his people's advancement. As a result of this conviction and the reality that the illiteracy rate in Gando was well over the national average of $81 \%$, he founded the Kéré Foundation and raised $\$ 50,000$ to build his first building, the Gando Primary School (figure 2). It won the prestigious Aga Khan Award for Architecture in 2004. He has since expanded the primary school and built a library, housing for teachers, and a secondary school for the people of Gando.

In the Gando Primary School and elsewhere, Kéré consistently embraces the traditional cultural practice of community members working together to build and repair local structures. For the construction of the Primary School, Kéré modified and improved conventional low-tech and sustainable clay brick techniques. In doing so, he was able to engage the local people and celebrate their long-established building techniques and methods, which are well-suited to the extreme climatic conditions. He then trained the local people to build using the improved methods. Kéré affirms that, "The Gando project was always connected to training the people..."22 and when questioned in the Aga Khan Award application about who provided the labor for the Primary School, Kéré's response is: "The population of Gando."23
The people of Gando built the school, and in the process learned a new skill by which they can earn a livable wage. Typically, young men from Gando must leave the village and even the country to make money, weakening the community in the process. Participating in the building of the school imparted useful and marketable knowledge to the local people. Kéré acknowledges that "...underlying the project was a strong didactic component: it was designed as an exemplar that would help the local community appreciate the value of traditional materials..."24 It worked. Soon after, the local government began to create employment opportunities by applying the same building methods to new public works projects in the city. ${ }^{25}$ The combination of a renewed respect for local traditions paired with contemporary knowledge of building with improved methods aligns with Kéré's belief that "...architecture can be a vehicle for collective expression and empowerment, which is why we work closely with local communities in all phases of design from planning to construction."26

Kéré's passionate connection to his native country, paired with his education and relationships abroad, allowed him to bridge two cultures and design a school which combines vital local teaching traditions with western influences. Kéré Architecture's proven methods mark a clear example of an architectural practice engaging critical, creative, and caring thinking to design a set of buildings that positively impact the lives of the people they touch.

\section{CONCLUSION}

As this brief overview indicates, MASS Design Group and Kéré Architecture are each doing a commendable, inspiring job of contributing to social welfare in their respective zones of influence. They are only a small part of a growing number of firms becoming involved in public interest architecture today, creating meaningful places that impact local communities.

When collaboration and dialogue are valued and prioritized in an organization, meaningful conversations between different stakeholders are likely to occur, and other-focused solutions naturally follow. Such methodology advances sensitive design solutions which deeply engage local social, economic and ecological issues and results in work that is inherently people-centered.

It is imperative to put people back into the architectural equation, and one can imagine an educational model which reflects this ideal. A paradigm that is analogous to the collaborative nature of contemporary practice fulfills the standards of a community of inquiry. Such pedagogy would naturally encourage, cultivate, and value the views of others, expanding the perspectives of students in the process.

Students educated in this way would be less willing to cede design control to software programs. They could wrestle 
creativity from the domain of the computer, and reclaim the human domain. In this new pedagogical model creativity would be understood as the means by which critical knowledge is applied with care. If students and faculty alike embrace improved, multidimensional thinking, they can then realize the power of the interdependent aspects of criticality, creativity, and caring to consistently produce thoughtful designs in the studio and beyond.

\section{ENDNOTES}

1 Stylianos Giamarelos, "Interdisciplinary Deflections: Histories of the Scientific Revolution in Alberto Perez-Gomez's Architecture and the Crisis of Modern Science," Journal of Architecture Education 60, no. 1 (2015): 20.

2 Bryan Bell et al. "Wisdom from the Field: Public Interest Architecture in Practice. A Guide to Public Interest Practices in Architecture," (Washington D.C.: AIA Latrobe Prize Final Report, 2011): 11.

3 Matthew Lipman, Thinking in Education, 2nd ed. (Cambridge: Cambridge University Press, 2003), 20.

4 Ibid.

5 Ashraf Salama, Spatial Design Education: New Directions for Pedagogy in Architecture and Beyond, (Farnham: Taylor and Francis, 2014), 78.

6 Linda Elder with Richard Paul, "Critical Thinking Development: A Stage Theory," Critical Thinking, accessed September 19, 2017, http://www.criticalthinking. org/pages/critical-thinking-development-a-stage-theory/483.

7 Lipman, Thinking in Education, 212.

8 Ibid., 219

9 Salama, Spatial Design Education, 160.

10 Ibid., 159

11 Lipman, Thinking in Education, 255.

12 Elder and Paul, "Critical Thinking Development"

13 Thomas Nadelhoffer et al., "Some Varieties of Humility Worth Wanting," Journal of Moral Philosophy 14 (2017): 182.

14 Lipman, Thinking in Education, 197.

15 Bell, "Wisdom from the Field," 2.

16 "About" MASS Design Group, accessed September 19, 2017, https://massdesigngroup.org/about.

17 "The Butaro District Hospital" MASS Design Group, accessed September 19, 2017, https://massdesigngroup.org/work/design/butaro-district-hospital.

18 Katie Gerfen, "Portfolio: MASS Design Group," Architect Magazine, 106, no. 5 (2017): 109

19 "African Design Centre" MASS Design Group, accessed September 19, 2017, https://massdesigngroup.org/work/research/african-design-centre.

20 John C. Gibbs, Moral Development and Reality: Beyond the Theories of Kohlberg, Hoffman, and Haidt, (New York: Oxford University Press, 2014), 105.

21 Matthew Schertz, "Empathic Pedagogy: Community of Inquiry and the Development of Empathy," Analytic Teaching 26, no. 1 (2014): 10.

22 Diébédo Francis Kéré, "How to Build with Clay...and Community," TEDCity2.0 (2013) https://www.ted.com/talks/ diebedo_francis_kere_how_to_build_with_clay_and_community.

23 Diébédo Francis Kéré et al., "Primary School," (Geneva: The Aga Khan Award for Architecture Project Brief, 2004) http://www.akdn.org/architecture/project/ primary-school.

24 Ibid.

25 Ibid.

26 "About" Kéré Architecture, accessed September 29, 2017, http://www.kerearchitecture.com/about/. 